\title{
Archives of Physical Medicine and Rehabilitation
}

journal homepage: www.archives-pmr.org

Archives of Physical Medicine and Rehabilitation 2013;94:1699-706

\section{Clinical Improvement and Resorption of Calcifications in Calcific Tendinitis of the Shoulder After Shock Wave Therapy at 6 Months' Follow-Up: A Systematic Review and Meta-Analysis}

Francesco Ioppolo, PhD, MD, ${ }^{a}$ Maria Tattoli, PhD, MD, ${ }^{a}$ Luca Di Sante, PhD, MD, ${ }^{a}$ Teresa Venditto, MD, ${ }^{\mathrm{b}}$ Lucrezia Tognolo, MD, ${ }^{\mathrm{b}}$ Mariachiara Delicata, MD, ${ }^{\mathrm{b}}$ Rosaria Sabrina Rizzo, MD, ${ }^{b}$ Gianluca Di Tanna, PhD, ${ }^{a}$ Valter Santilli, MD ${ }^{a, b}$

From the ${ }^{a}$ Physical Medicine and Rehabilitation Unit, Azienda Policlinico Umberto I, Rome; and ${ }^{b}$ Board of Physical Medicine and Rehabilitation, Department of Orthopaedic Science, "Sapienza" University, Rome, Italy.

\begin{abstract}
Objectives: To evaluate the effectiveness of shock wave therapy (SWT) for functional improvement and the reduction of pain in patients with calcific tendinitis of the shoulder, and to determine the rate of disappearance of calcifications after therapy at 6 months' follow-up.

Data Sources: Articles were searched from the Cochrane Library, MEDLINE, Embase, CINAHL, and Ovid database.

Study Selection: We included randomized controlled trials from 1992 to 2011, and their quality was assessed using the Physiotherapy Evidence Database (PEDro) scale.

Data Extraction: Studies were evaluated by 2 independent reviewers for their methodologic quality. Disagreements were settled by a third reviewer. Data were then extracted and cross-checked for accuracy. The reviewers were not blinded to the authors of the articles.

Data Synthesis: In 4 of the 6 studies included for review, the resorption of calcifications was evaluated using meta-analysis because the studies had 2 treatment groups, while the other 2 studies were analyzed descriptively because they had 3 treatment groups. Fixed- and random-effects models were used to meta-analyze total and partial resorption ratios, and $\mathrm{I}^{2}$ statistics were calculated to assess heterogeneity.

Conclusions: We found a clinical improvement with a pooled total resorption ratio of 27.19 (95\% confidence interval [CI], 7.20-102.67) and a pooled partial resorption ratio of 16.22 (95\% CI, 3.33-79.01). SWT increases shoulder function, reduces pain, and is effective in dissolving calcifications. These results were maintained over the following 6 months.
\end{abstract}

Archives of Physical Medicine and Rehabilitation 2013;94:1699-706

(C) 2013 by the American Congress of Rehabilitation Medicine

Calcific tendinitis of the shoulder (CTS) is an enthesopathy that is characterized by inflammation around calcium hydroxyapatite crystal deposits, usually localized in the supraspinatus tendon near its insertion. ${ }^{1}$ The prevalence of asymptomatic calcifications in the rotator cuff is reported to be between $2.7 \%$ and $20 \%$. $^{2}$

The mechanisms underlying the etiology of intratendinous deposits of carbonated apatite are not fully understood. ${ }^{3}$ The disorder progresses through 4 phases and ends with complete restitution. ${ }^{4}$

No commercial party having a direct financial interest in the results of the research supporting this article has or will confer a benefit on the authors or on any organization with which the authors are associated.
Gartner and Simons ${ }^{5}$ classified these calcifications in relation to their radiologic features: type I, clearly circumscribed and dense, formative; type II, clearly circumscribed, translucent, cloudy, and dense; type III, cloudy and translucent, resorptive and with a high tendency to spontaneous resolution.

CTS is painful in $50 \%$ of patients, and this pain may interfere with sleep and compromise activities of daily living. ${ }^{6,7}$

Conservative treatment ${ }^{8}$ includes therapeutic exercise, ${ }^{9}$ analgesic and nonsteroidal anti-inflammatory drugs, transcutaneous electrical nerve stimulation, ${ }^{10}$ steroid injections, ${ }^{11}$ and shock wave therapy (SWT). ${ }^{12,13}$ If conservative treatment fails, arthroscopic or open surgery is performed. 
Several studies ${ }^{14-16}$ have demonstrated the efficacy of SWT for pain relief, clinical improvement, and disappearance of calcifications in patients with CTS. The cost of SWT is higher than other conservative treatments, but less than a surgical procedure and the ensuing rehabilitation. Moreover, patients who undergo surgery often need to take a lengthy leave of absence from work. ${ }^{17,18}$

Three types of shock wave generators are used in medical practice: electrohydraulic, electromagnetic, and piezoelectric. ${ }^{19}$ We may distinguish between extracorporeal shock waves (ESWs) and radial shock waves (RSWs). ESW therapy is based on the use of shock waves by single pressure pulses of a microsecond duration, and these can be guided by ultrasound or radiographs to focus on a specific site. Alternatively, RSW therapy is a low- to medium-energy shock wave that is pneumatically generated through the acceleration of a projectile inside the handpiece of the treatment device and then transmitted radially from the tip of the applicator to the target zone. Pressure and the density of energy are observed to undergo a decrease by the third power of the penetration depth in the tissue. ESWs are defined as "focused" because waves are centered and their focal point is on the target zone, whereas the focal point is not centered in RSWs. ${ }^{16}$

Energy flux density (EFD), recorded as joules per area, is the energy delivered at the focal point of the shock wave per impulse. The number and EFD of the single impulses and the geometric measurement of the focal point define the effective total energy of treatment.

SWT can be classified according to its energy levels. Lowenergy shock waves have an EFD of up to $.08 \mathrm{~mJ} / \mathrm{mm}^{2}$; moderateenergy shock waves, an EFD of between .09 and $.28 \mathrm{~mJ} / \mathrm{mm}^{2}$; and high-energy shock waves, an EFD of up to $0.6 \mathrm{~mJ} / \mathrm{mm}^{2} .^{20,21} \mathrm{~A}$ simpler classification distinguishes between low-energy ESW therapy having an EFD of less than $.12 \mathrm{~mJ} / \mathrm{mm}^{2}$, and high-energy ESW having an EFD between .12 and $.38 \mathrm{~mJ} / \mathrm{mm}^{2} .^{20,22}$

To date, it is not clear what energy level is needed to promote the disappearance of calcific deposits. Indeed, many studies show that a high energy level is more effective than a low energy level for clinical improvement, relief of pain, and resorption of calcifications.

The objective of this review was to evaluate the effectiveness of SWT for the treatment of CTS. Therefore, we analyzed all randomized controlled trials (RCTs) published from 1992 (year in which a case report described 6 patients with calcifying tendinopathy who were treated with shock waves). ${ }^{23}$ We also assessed the clinical improvement and rate of disappearance of calcific deposits after SWT at 6 months' follow up.

\begin{tabular}{|l|}
\hline List of abbreviations: \\
CG control group \\
CI confidence interval \\
CMS Constant-Murley Scale \\
CTS calcific tendinitis of the shoulder \\
EFD energy flux density \\
ESW extracorporeal shock wave \\
MCID minimal clinically important difference \\
PEDro Physiotherapy Evidence Database \\
RCT randomized controlled trial \\
RR resorption ratio \\
RSW radial shock wave \\
SWT shock wave therapy \\
VAS visual analog scale \\
\hline
\end{tabular}

\section{Methods}

\section{Criteria for considering studies for this review}

\author{
Types of studies \\ - RCTs \\ - English-language studies
}

\section{Types of participants}

Inclusion in this review was restricted to trials with participants meeting the following criteria:

1. Adults $>18$ years of age

2. Shoulder pain or tenderness from calcific tendonitis in patients with type I or II calcification according to the radiographic classification of Gartner and Simons. ${ }^{5}$

Exclusion was restricted to trials with participants not meeting the following criteria:

1. History of significant trauma or systemic inflammatory conditions such as rheumatoid arthritis, hemiplegic shoulders, postoperative shoulder pain, and pain in the shoulder region as part of complex myofascial neck/shoulder arm pain

2. Rotator cuff tear

3. Presence of type III (cloudy and transparent) calcifications according to the radiographic classification of Gartner and Simons. ${ }^{5}$

\section{Types of interventions}

All RCTs that compared SWT with placebo or no treatment were considered.

\section{Types of outcome measures}

Our outcome measures were clinical improvement, evaluated by shoulder functional scales, and resorption of calcific deposits, defined through radiographic examinations.

\section{Search methods for identification of studies}

MEDLINE, Embase, CINAHL, Ovid database, Physiotherapy Evidence Database (PEDro), and the Cochrane Library were searched for the period from August $1992^{23}$ through December 2011 (appendix 1).

\section{Data extraction and analysis}

Characteristics of extraction data are presented in table 1. Studies were evaluated by 2 independent reviewers for their methodologic quality. Disagreements were settled by a third reviewer. Data were then extracted and cross-checked for accuracy. The reviewers were not blinded to the authors of the articles.

In the studies by Hearnden, ${ }^{24} \mathrm{Hsu},{ }^{25}$ Cacchio, ${ }^{16}$ and Cosentino $^{26}$ and colleagues, the resorption of calcific deposits was evaluated using meta-analysis because the studies had 2 treatment groups, while the studies by Peters ${ }^{27}$ and Gerdesmeyer ${ }^{28}$ and colleagues were analyzed descriptively because they considered 3 treatment groups (see table 1). Fixed- and random-effects models ${ }^{29}$ were used to meta-analyze total and partial resorption ratios, and $\mathrm{I}^{2}$ statistics were calculated to assess heterogeneity. Stata software ${ }^{\mathrm{a}}$ was used for the statistical analysis, and $95 \%$ confidence intervals (CIs) were reported. 
Table 1 Characteristics of selected studies

\begin{tabular}{|c|c|c|c|c|c|c|c|c|c|c|c|c|c|}
\hline $\begin{array}{l}\text { First Author, } \\
\text { Year }\end{array}$ & $\mathrm{N}$ & $\begin{array}{l}\text { Sex } \\
\text { (W/M) }\end{array}$ & $\begin{array}{l}\text { HS } \\
(\mathrm{mo})\end{array}$ & Follow-Up & Groups & $\begin{array}{l}\text { Outcome } \\
\text { Measure }\end{array}$ & $P$ & TR ESG & PR ESG & NR ESG & TR CG & PR CG & NR CG \\
\hline $\begin{array}{l}\text { Hearnden, }{ }^{24} \\
2009\end{array}$ & 20 & NR & 12 & $\begin{array}{l}\text { T1 (1st wk) } \\
\text { T2 (6th wk) } \\
\text { T3 (6th mo) }\end{array}$ & $\begin{array}{l}\text { ESG: } 2000 \times .28 \mathrm{~mJ} / \mathrm{mm}^{2} \\
\text { CG: } 20 \times .03 \mathrm{~mJ} / \mathrm{mm}^{2}\end{array}$ & $\begin{array}{l}\text { CMS } \\
\text { VAS }\end{array}$ & $<.03$ & $6 / 11$ & 0 & $5 / 11$ & 0 & 0 & $9 / 9$ \\
\hline $\mathrm{Hsu}^{25} 2008$ & 46 & $27 / 19$ & 3 & $\begin{array}{l}\text { T1 (6th wk) } \\
\text { T2 (12th wk) } \\
\text { T3 (6th mo) } \\
\text { T4 (12th mo) }\end{array}$ & $\begin{array}{l}\text { ESG: } 1000 \times .55 \mathrm{~mJ} / \mathrm{mm}^{2} \\
\text { CG: NR }\end{array}$ & $\begin{array}{l}\text { CMS } \\
\text { VAS }\end{array}$ & $<.05$ & $7 / 33$ & $11 / 33$ & $15 / 33$ & 0 & 0 & $13 / 13$ \\
\hline $\begin{array}{c}\text { Cacchio, }^{16} \\
2006\end{array}$ & 90 & $35 / 55$ & 6 & $\begin{array}{l}\text { T1 (1st wk) } \\
\text { T2 (6th mo) }\end{array}$ & $\begin{array}{l}\text { ESG: } 2500 \times .10 \mathrm{~mJ} / \mathrm{mm}^{2} \\
\text { CG: } 25 \times \mathrm{NR}->\end{array}$ & $\begin{array}{l}\text { UCLA } \\
\text { VAS }\end{array}$ & $<.05$ & $39 / 45$ & $6 / 45$ & 0 & 0 & 0 & $45 / 45$ \\
\hline Peters, ${ }^{27} 2004$ & 90 & $55 / 35$ & 6 & (6th mo) & $\begin{array}{l}\text { ESG-1: } 1500 \times .15 \mathrm{~mJ} / \mathrm{mm}^{2} \\
\text { ESG-2: } 1500 \times .44 \mathrm{~mJ} / \mathrm{mm}^{2} \\
\text { CG: } 0.00 \mathrm{~mJ} / \mathrm{mm}^{2}\end{array}$ & None & $<.001$ & $\begin{array}{l}\text { 31/31 HEL } \\
0 / 31 \mathrm{LEL}\end{array}$ & $\begin{array}{l}0 \text { HEL } \\
0 \text { LEL }\end{array}$ & $\begin{array}{l}0 \text { HEL } \\
31 / 31 \mathrm{LEL}\end{array}$ & 0 & 0 & $29 / 29$ \\
\hline $\begin{array}{l}\text { Cosentino, } \\
2003\end{array}$ & 70 & $43 / 27$ & 10 & $\begin{array}{l}\text { T1 (end of Tr) } \\
\text { T2 (4th wk) } \\
\text { T3 (6th mo) }\end{array}$ & $\begin{array}{l}\text { ESG: } 1200 \times .28 \mathrm{~mJ} / \mathrm{mm}^{2} \\
\text { CG: } 120 \times 0 \mathrm{~mJ} / \mathrm{mm}^{2}\end{array}$ & CMS & $<.001$ & $11 / 35$ & $14 / 35$ & $10 / 35$ & 0 & 0 & $35 / 35$ \\
\hline $\begin{array}{l}\text { Gerdesmeyer, }^{28} \\
\quad 2003\end{array}$ & 144 & $87 / 57$ & 6 & $\begin{array}{l}\text { T1 (3rd mo) } \\
\text { T2 (6th mo) } \\
\text { T3 (12th mo) }\end{array}$ & $\begin{array}{l}\text { ESG-1: } 1500 \times .32 \mathrm{~mJ} / \mathrm{mm}^{2} \\
\text { ESG-2: } 6000 \times .08 \mathrm{~mJ} / \mathrm{mm}^{2} \\
\text { CG: NR }\end{array}$ & $\begin{array}{l}\text { CMS } \\
\text { VAS }\end{array}$ & $<.05$ & $\begin{array}{l}29 / 48 \text { HEL } \\
10 / 48 \text { LEL }\end{array}$ & $\begin{array}{l}0 \text { HEL } \\
0 \text { LEL }\end{array}$ & $\begin{array}{l}\text { 19/48 HEL } \\
\text { 38/48 LEL }\end{array}$ & $5 / 48$ & 0 & $43 / 48$ \\
\hline
\end{tabular}

Abbreviations: CG, control group; ESG, experimental group; HEL, high energy level; HS, history of symptoms; LEL, low energy level; M, men; NR, not reported; PR, partial resorption; Tr, treatment; TR, total resorption; UCLA, University of California-Los Angeles; W, women.

We considered 3 parameters in both the experimental group and the control group (CG): total resorption, partial resorption, and no resorption.

Methodologic quality was evaluated via the PEDro scale (http://www.pedro.org.au). The exact criteria assessed are found in figure 1. Elements were only scored as "yes" where quality clearly met the specified criteria. Where criteria were not met or were unclear, a "no" was scored. Again, this was independently undertaken by 2 of the reviewers.

\section{Results}

The literature search identified 28 potentially relevant articles, which were assessed by their abstracts. Sixteen abstracts were excluded as irrelevant. We selected 12 full texts; of these, 6 were excluded. The remaining 6 , involving trials with 460 patients, were evaluated because they met our inclusion criteria (fig 2).

\section{Study quality}

The results of the PEDro rating are shown in figure 1 . The quality of the studies as determined via the PEDro rating scale ranged from 2 to 8 out of a possible score of 10 . Three ef $^{26-28}$ studies did not report whether groups were equivalent at baseline. Imbalances between groups in key prognostic variables at baseline (variables that have the potential to influence outcomes) may subsequently bias treatment outcomes. Four of the 6 studies did not use an intention-to-treat analysis. ${ }^{24-27}$ The study by Cosentino et $\mathrm{al}^{26}$ did not include at least 1 key outcome measure from at least $85 \%$ of participants allocated to each group. Only 2 clinical trials ${ }^{16,28}$ provided estimates of the size of the treatment effects.

\section{SWT compared with placebo or sham treatment}

\section{Clinical evaluation}

The authors of the studies evaluated pain and function using different types of scales.

For shoulder disease, Tashjian et $\mathrm{al}^{30}$ have calculated the minimal clinically important difference (MCID; ie, the smallest change in a measurement that signifies an important improvement in a symptom) and the patient acceptable symptom state (symptom state that a patient considers acceptable) for the visual analog scale (VAS). The authors postulated that a $1.4-\mathrm{cm}$ improvement on the VAS in patients represents an MCID. The VAS is a horizontal line, $10 \mathrm{~cm}$ in length, with $0 \mathrm{~cm}$ labeled "no pain" and $10 \mathrm{~cm}$ labeled "worst pain I have ever had." Patients mark the point on the line that they feel represents their perception of their current state. ${ }^{31}$ The authors also determined that if patients report a pain score of 0 to $3 \mathrm{~cm}$ on a $10-\mathrm{cm}$ VAS, their pain level is acceptable. ${ }^{30}$ The VAS was used in $3^{16,25,28}$ of the 6 studies of this systematic review to compare pain before treatment and at 6 months' follow-up. We found that in the treated groups, the average change on the VAS was greater than MCID value for shoulder disease that Tasjian et $\mathrm{al}^{30}$ established as $1.4 \mathrm{~cm}$. Therefore, the reduction of pain was clinically significant at 6 months after treatment, and the value greater than $1.4 \mathrm{~cm}$ shows that patients find the pain acceptable.

The Constant-Murley Scale (CMS) is the scoring system used to assess shoulder function in 4 of the studies being reviewed. It combines physical examination tests with subjective evaluations by the patients and consists of 35 points and 65 points, respectively. Its strength is the method of its application, which is quite clearly described, and its being an improvement on preexisting scales. ${ }^{32}$

A recent review ${ }^{33}$ of the psychometric evidence relating to the Constant-Murley score has shown that its administration perhaps requires further standardization. Indeed, clinicians who 


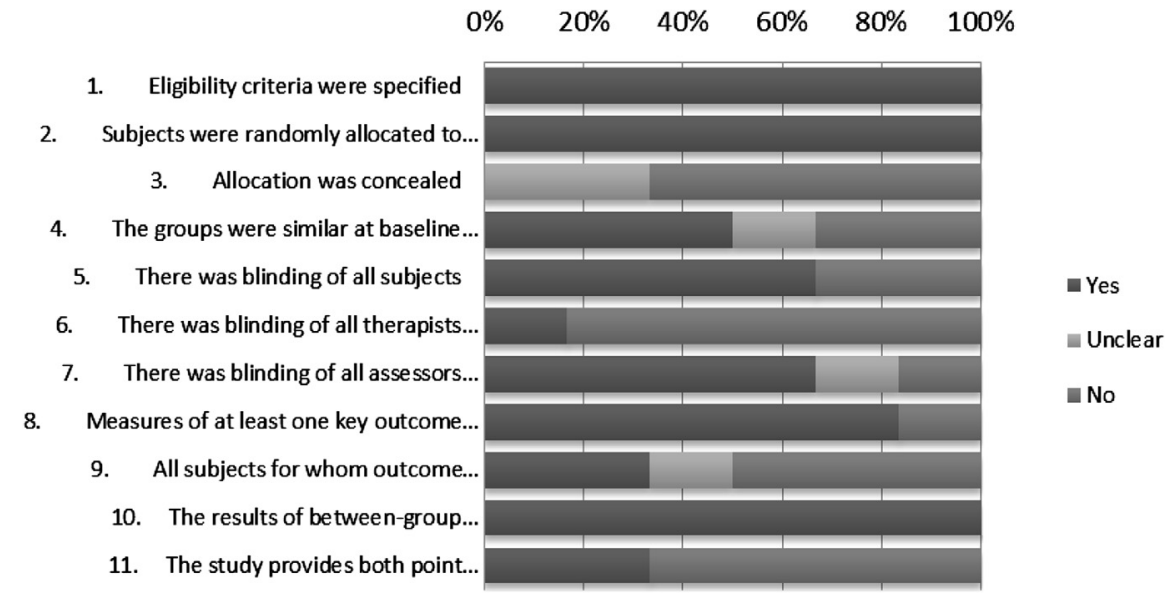

Fig 1 PEDro quality items assessment. Percentages of "yes," "no," and "unclear" according to the evaluation of single items.

use the original version of the CMS should keep in mind that major psychometric properties such as content validity and MCID have not been demonstrated. Since the CMS is often used for research purposes, the MCID information would help to establish clinically important differences for sample size calculations.

In the study by $\mathrm{Hsu}$ et $\mathrm{al}^{25}$ the Constant-Murley score in the experimental group increased from 57.3 before treatment to 82.8 at 6 months, whereas in the CG it essentially remained unchanged over time (from a score of 56.2 before SWT to 54.3 at $6 \mathrm{mo}$ ). Improvement after treatment was statistically significant for the SWT group but not for the CG.

Hearden et al's study ${ }^{24}$ showed that in $45 \%$ of the treated patients, the Constant-Murley score increased by $11 \%$ at 6 months after treatment, whereas in the CG there was no improvement in the score.

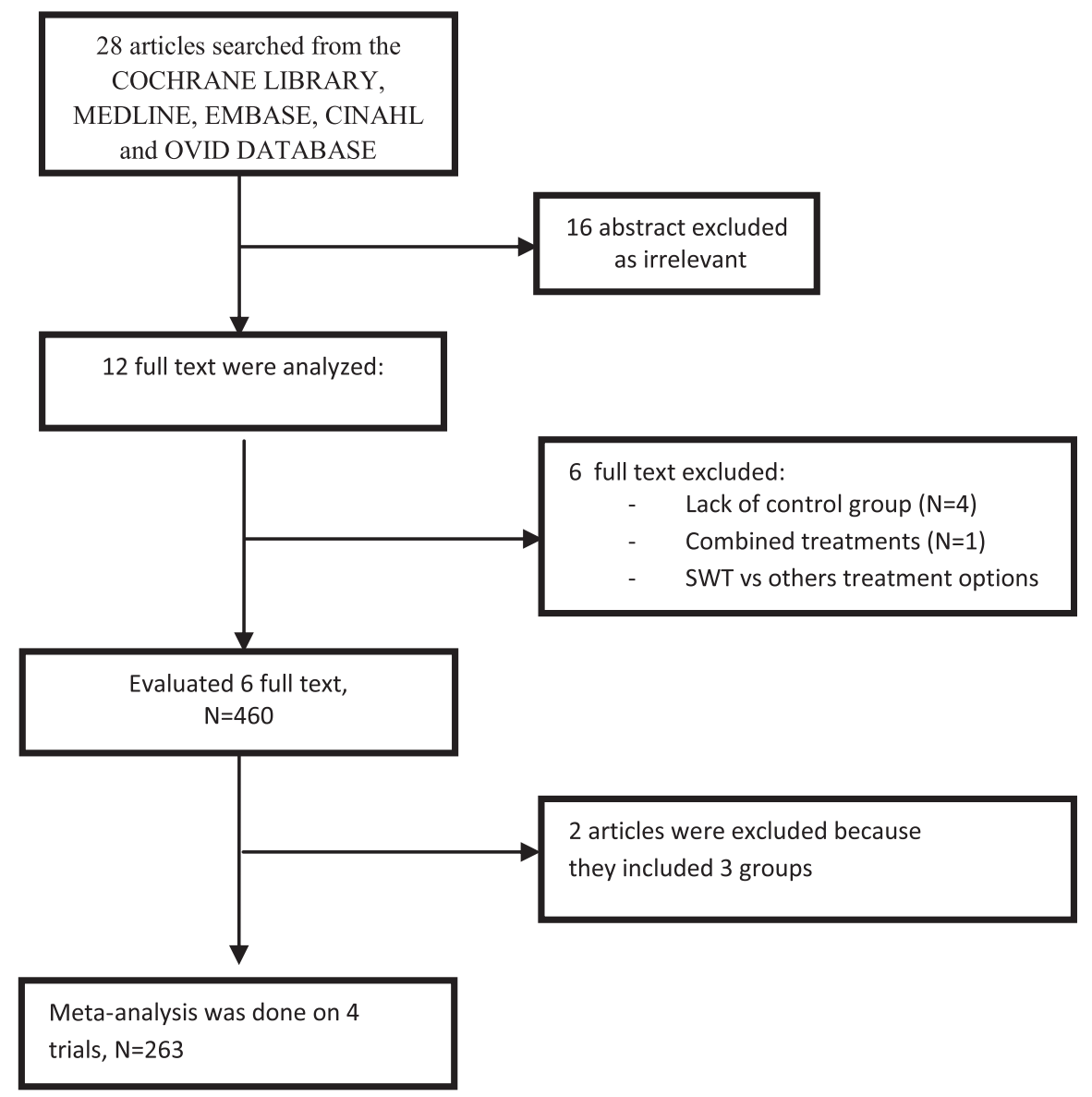

Fig 2 Flowchart. 
In the study by Gerdesmeyer et al, ${ }^{28}$ both low-energy and highenergy interventions were superior to sham treatment, and in a secondary analysis the high-energy intervention appeared to be superior to the low-energy intervention. In 3 groups, there was a mean change of the Constant-Murley score of 31.0 (high energy), 15.0 (low energy), and 6.6 (sham) at 6 months' follow-up compared with baseline.

In the study by Cosentino et $a,^{26}$ the mean value of the Constant-Murley score in the treated group was 45 points at the start of the study, and there was a mean increase of $69 \%$ at 6 months' follow-up, whereas in the CG in the ConstantMurley score, no significant increase in shoulder function was seen.

Cacchio et $\mathrm{al}^{16}$ in their study used the University of California-Los Angeles Shoulder Rating Scale ${ }^{34}$ to assess shoulder function, and have shown that there is a significant increase in the mean score in the experimental group. This scale is used to evaluate the patient's pain, function, forward flexion, strength, and satisfaction. These 5 items are rated on ordinal scales of different lengths and scoring points. The maximum total score possible is 35 , with a higher score indicating better shoulder function. The outcome score is defined as follows: 34 to 35 points, excellent; 29 to 33 points, good; 21 to 28 points, mild; and 20 points or less, poor.

In conclusion, the selected articles reported that high-energy SWT is effective in the treatment of CTS, pain relief, and functional restoration when measured at 6 months' follow-up.

\section{Resorption of calcific deposits: results of meta-analysis}

The mechanism of calcium deposit dissolution is not clearly known. Calcium deposits are eliminated after SWT through a molecular mechanism of absorption associated with improved circulation at the tendon-bone junction. ${ }^{35}$

Meta-analysis of studies evaluated the radiologic rate of resorption of calcific deposits at 6 months' follow-up. We found that SWT is superior to no treatment or placebo for partial and total resorption.

With regard to total resorption, 4 studies ${ }^{16,24-26}$ were metaanalyzed, with a pooled resorption ratio (RR) of 27.19 (95\% CI, 7.20-102.67) and a heterogeneity test that was not statistically significant $(P=.552)$. Pooling results from the 3 studies $^{16,25,26}$ that reported partial resorption, we obtained an RR of 16.22 (95\% CI, 3.33-79.01). Estimates were not heterogeneous across studies $(P=.845)$ (figs 3 and 4$)$. Given that we have not rejected the hypothesis of homogeneity across studies, we reported results from fixed-effects models. In the figures, we reported fixed- and random-effects models as a mean of sensitivity analysis to better assess the robustness of our results.

In the study by Hearnden et al, ${ }^{24} 54.5 \%$ of patients receiving SWT showed no signs of calcific deposits at 6 months' follow-up. Cacchio $^{16}$ showed that radial SWT is effective in dissolving calcifications 1 week after the end of treatment. Indeed, there was a total resorption of $86.6 \%$ and a partial resorption of $13.4 \%$ in the treatment group. As shown in the study by Rompe et al, ${ }^{18}$ a complete disappearance of calcium deposits was found more frequently in patients with type II calcifications according to Gartner and Simons' classification. ${ }^{5}$ In Cacchio's study, ${ }^{16}$ resorption was maintained until 6 months' follow-up. ${ }^{18}$

The study by $\mathrm{Hsu}$ et $\mathrm{al}^{25}$ reported for the experimental group a total resorption rate of $21.2 \%$ and a partial resorption rate of $33.3 \%$, whereas the study by Cosentino ${ }^{26}$ reported a total resorption rate of $31.4 \%$ and a partial resorption rate of $40 \%$.
Resorption of calcific deposits: results of descriptive analysis Peters et $\mathrm{al}^{27}$ reported that therapy is more effective in the highenergy $\left(.44 \mathrm{~mJ} / \mathrm{mm}^{2}\right)$ group than in the low-energy $\left(.15 \mathrm{~mJ} / \mathrm{mm}^{2}\right)$ group in dissolving calcifications at 6 months from the end of treatment. They observed no residual calcifications with no recurrence of pain in the high-energy group, whereas in the lowenergy group all subjects showed residual deposits, and $87 \%$ of patients experienced a recurrence of pain.

Gerdesmeyer ${ }^{28}$ compared high-energy $\left(.32 \mathrm{~mJ} / \mathrm{mm}^{2}\right)$ and lowenergy $\left(.08 \mathrm{~mJ} / \mathrm{mm}^{2}\right)$ ESW therapy and extended the follow-up to 12 months. They observed a better response in subjects treated with high-energy ESW, with a rate of $60 \%$ of complete disappearance of calcific deposits at 6 months' follow-up and $86 \%$ at 12 months' follow-up, whereas in the low-energy treatment group the rate of dissolution was $21 \%$ at 6 months and $25 \%$ at 12 months.

\section{Discussion}

CTS is a common cause of shoulder pain producing disability. ${ }^{18,36}$ Indeed, the compromised mobility of the shoulder limits daily activities such as dressing, personal hygiene, eating, and work. In addition, shoulder pain is often associated with disturbed sleeping and thus affects mood and concentration.

The results of our study show the effectiveness of SWT in reducing pain, increasing shoulder function, and dissolving calcifications at 6 months' follow-up.

Uhthoff et $\mathrm{al}^{37}$ described 4 distinctive phases of the disease's progression. In the precalcific phase, there is an asymptomatic metaplasia of the tendinous tissue into fibrocartilage. In the formative phase, calcium is deposited in the tendon, and the patient may be asymptomatic or have pain either at rest or related to movement. The resorptive phase, usually the most painful phase, is characterized by cell-mediated resorption of calcium deposits by macrophages and multinucleated giant cells. The repair phase, associated with healing and repair, may be accompanied by some residual pain and stiffness.

Gartner and Simons ${ }^{5}$ reported that calcifications disappear spontaneously over a period of 3 years in $33 \%$ of patients with Gartner type I and in $71 \%$ with Gartner type II, but the time required for spontaneous disappearance of calcifications is so long that it adversely affects the patient's quality of life. Bosworth ${ }^{6}$ described the disappearance of calcifications in $9.3 \%$ of patients within 3 years of the initial diagnosis, whereas Wagenhauser ${ }^{38}$ observed the disappearance of calcifications in $27.1 \%$ of patients after 10 years.

According to Geschwend et al, ${ }^{39}$ more than $90 \%$ of patients can be cured by conservative treatments, and SWT could be an alternative to failed conservative therapies before surgery.

Indeed, Daecke et $\mathrm{al}^{40}$ reported a clinical improvement and a significant correlation between the dose of energy and radiologic effectiveness after 1 or 2 sessions of high-energy shock waves. Loew $^{41}$ and Rompe ${ }^{18}$ and colleagues observed that there was an increase of the Constant-Murley score 12 weeks after low-energy SWT, although the improvement was inferior to that observed in the high-energy treatment group.

In contrast to these studies, Albert et $\mathrm{al}^{42}$ observed that highenergy SWT significantly improves symptoms in refractory CTS after 3 months of follow-up, but the size of the calcific deposit remains unchanged in most patients. Indeed, radiographs at 3 months showed that the calcific deposits had only disappeared in $15 \%$ and $5 \%$ of patients in the high- and low-energy groups, respectively.

In our review, we tried to evaluate the relationship between SWT and clinical improvement, and to quantify the possible effects of SWT on resorption of shoulder calcific deposits. We 
ID

$\mathrm{RR}(95 \% \mathrm{Cl})$

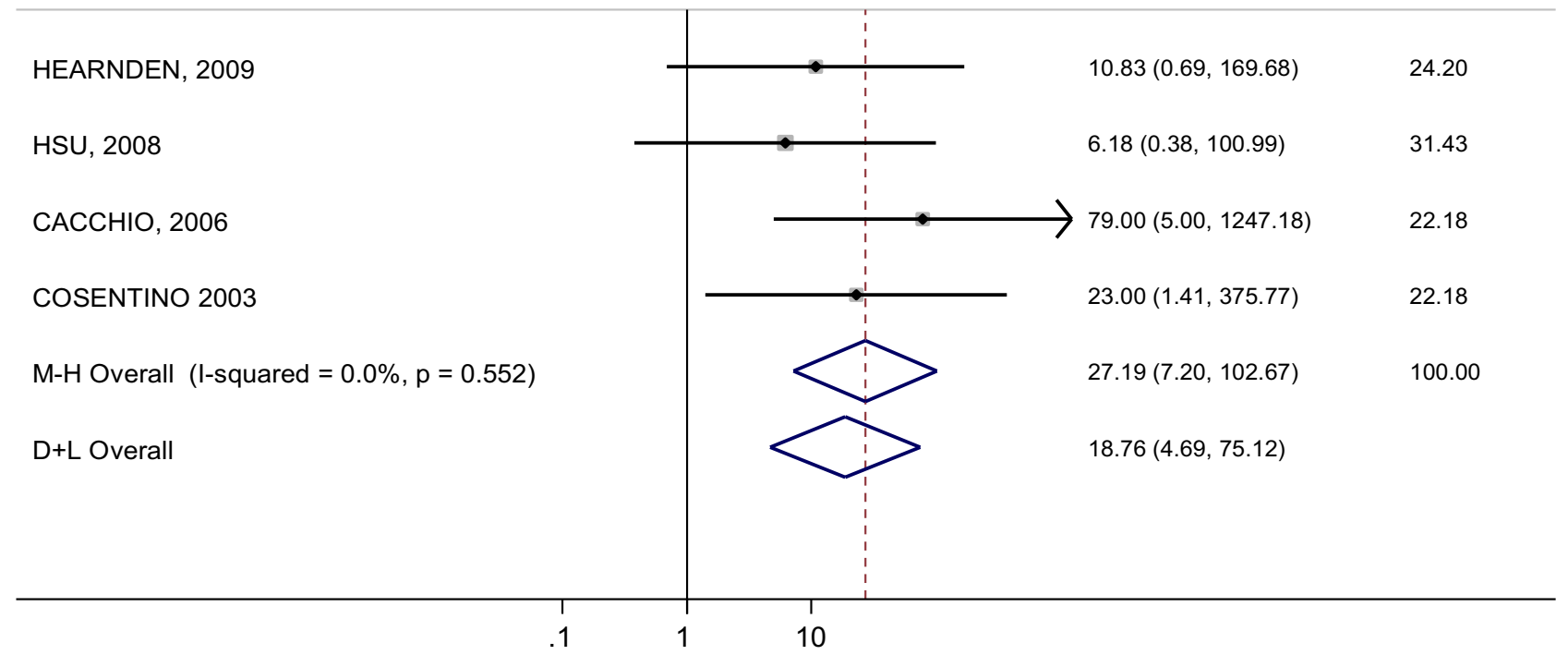

Fig 3 Forest plot of total resorption of shoulder calcific deposits. Both fixed (Mantel-Haenszel [M-H]) and random (DerSimonian Laird [D+L]) effects models are presented.

found a marked improvement in symptoms at 6 months' followup, and that the effect of this treatment is resorption of calcifications. The studies submitted to meta-analysis ${ }^{16,24-26}$ in which a high energy level was used have shown better results for the experimental group compared with the CG. Also Peters ${ }^{27}$ and Gerdesmeyer $^{28}$ and colleagues have observed that SWT is more effective in patients receiving high energy compared with those treated with low energy.
Weight

Study

$\operatorname{RR}(95 \% \mathrm{Cl})$

$(\mathrm{M}-\mathrm{H})$

HSU, 2008

CACCHIO, 2006

COSENTINO 2003

$\mathrm{M}-\mathrm{H}$ Overall $(\mathrm{I}$-squared $=0.0 \%, \mathrm{p}=0.845)$

$D+L$ Overall

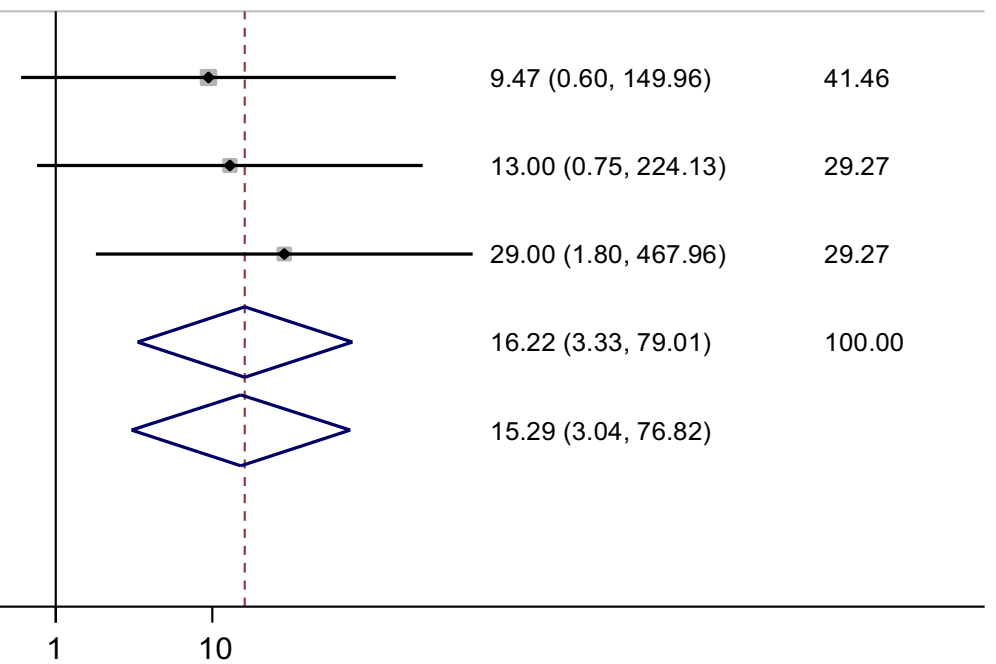

Fig 4 Forest plot of partial resorption of shoulder calcific deposits. Both fixed (Mantel-Haenszel [M-H]) and random (DerSimonian Laird [D+L]) effects models are presented. 


\section{Study limitations}

It would be of interest to determine whether and, if so, to what degree there exists a correlation between decreased pain and functional recovery, on the one hand, and the resorption of calcific deposits, on the other. To date, the results of many clinical trials on the effectiveness of SWT for CTS are insufficient to establish a statistical relationship between clinical change and disappearance of calcifications at follow-up.

Many patients, and even some physicians, believe that the effect of treatment with extracorporeal SWT is due to the "destruction of calcific deposits." However, that may not in fact be the case, as can be deduced from the existence of a certain number of patients who experience a decrease in pain even though there is no corresponding disappearance of calcific deposits.

Reflecting on the manifestation of pain reduction, functional recovery, and reabsorption of calcific deposits over time, we may say that the most immediate consequence of treatment with SWT is the diminution of pain, and this can be explained by a "washout mechanism" of chemical inflammatory mediators and a nociceptive inhibition (gate control theory). ${ }^{41,43}$

Functional recovery commences at the same time as pain reduction and becomes more evident over time. It could be explained through the trophic-metabolic effect that SWT has on tendons that are in close proximity to calcifications, which is mediated by an increase in blood vessels in the area involved. ${ }^{44,45}$

In general, most studies ${ }^{16,24-28}$ measure the effects that shock waves have on reabsorption only at a distance of 3 months after the conclusion of treatment, for the simple reason that this phenomenon is not held to be "premature." Consequently, it is possible that the effects of resorption may follow a temporal progression parallel to that of functional recovery.

Two of the studies ${ }^{25,28}$ considered allow for what must for the time being remain a hypothesis regarding the correlation between the improvement of CMS at 6 months and the volumetric diminution of the calcific deposit at 6 months. The studies by $\mathrm{Hsu}^{25}$ and Gerdesmeyer $^{28}$ and colleagues allowed us to investigate this. We found that there is a slope of .66 between the delta score of the CMS and the delta score for the size of calcific deposits (defined as the difference between the 6-month measurement and baseline values). Therefore, an increase of 1 unit in the CMS delta score is associated with a decrease of .66 in the delta score of the calcium deposit. This finding seems to suggest that reducing the size of calcific deposits is associated with a clinical improvement.

Lastly, the literature shows that SWT is a safe treatment. Indeed, in the literature, minor complications of SWT such as pain in the shoulder, local soft tissue swelling, cutaneous erosions, erythema, and local subcutaneous hematomas have been reported. Durst et $\mathrm{al}^{46}$ reported 1 case of osteonecrosis of the humeral head after SWT.

As reported above, the effective total energy of a treatment depends on the number and EFD of the single impulses and the geometric measurement of the focal point. However, there is no consensus as to the appropriate number of sessions and impulses of SWT. Indeed, the studies of this systematic review used a different number of sessions and impulses. Consequently, it is possible that the higher the number of impulses, the higher its effectiveness.

\section{Conclusions}

Our review allows us to state that SWT reduces pain and increases shoulder function, and is effective in dissolving calcifications.
Moreover, the studies report that treatment effects were maintained over the following 6 months. The methodologic quality of the 6 trials on SWT for CTS appeared to be low. All trials were randomized, but only 2 studies ${ }^{16,28}$ were deemed to qualify as a methodologically high-quality RCT. Indeed, these trials provided estimates of the size of treatment effects and used intention-to-treat analysis, which is an essential feature of an RCT. However, further studies are needed to standardize SWT parameters (EFD, number of sessions and impulses) to be used in medical protocols.

\section{Supplier}

a. StataCorp LP, 4905 Lakeway Dr, College Station, TX 77845.

\section{Keywords}

Calcinosis; High-energy shock waves; Rehabilitation; Rotator cuff; Shoulder; Tendinopathy

\section{Corresponding author}

Francesco Ioppolo, $\mathrm{PhD}$, MD, Department of Physical Medicine and Rehabilitation, Piazzale Aldo Moro 3, 00185, Rome, Italy. E-mail address: francescoioppolo@yahoo.it.

\section{Appendix 1 Search methods for identification of studies}

1. Calcific AND "tendinopathy" [MeSH Terms] OR "tendinopathy" [All Fields] OR "tendinitis" [All Fields] OR "tendonitis" [All Fields] rotator cuff, supraspinatus tendon [All Fields])

2. Shoulder pain AND 1("shock" [MeSH Terms] OR "shock" [All Fields]) AND wave [All Fields]

3. Extracorporeal OR 3 AND 1-2

4. Radial OR 3 AND 1-2

5. Clinical Trial [ptyp] OR Randomized Controlled Trial [ptyp] OR Controlled Clinical Trial [ptyp]

6. Physical therapy AND 1-2

7. Rehabilitation AND 1-2

\section{References}

1. Wainner RS, Hasz M. Management of acute calcific tendinitis of the shoulder. J Orthop Sports Phys Ther 1998;27:231-7.

2. Krasny C, Enenkel M, Aigner N, Wlk M, Landsiedl F. Ultrasound-guided needling combined with shock-wave therapy for the treatment of calcifying tendonitis of the shoulder. J Bone Joint Surg Br 2005;87:501-7.

3. Faure G, Daculsi G. Calcified tendinitis: a review. Ann Rheum Dis 1983;42(Suppl 1):49-53.

4. Uhthoff HK. Calcifying tendinitis. Ann Chir Gynaecol 1996;85:111-5.

5. Gartner J, Simons B. Analysis of calcific deposits in calcifying tendinitis. Clin Orthop Relat Res 1990;(254):111-20.

6. Bosworth B. Calcium deposits in the shoulder and subacromial bursitis: a survey of 12122 shoulders. JAMA 1941;116:2477-89.

7. McKendry RJ, Uhthoff HK, Sarkar K, Hyslop PS. Calcifying tendinitis of the shoulder: prognostic value of clinical, histologic, and radiologic features in 57 surgically treated cases. J Rheumatol 1982;9:75-80.

8. Gimblett PA, Saville J, Ebrall P. A conservative management protocol for calcific tendinitis of the shoulder. J Manipulative Physiol Ther 1999;22:622-7. 
9. Bang MD, Deyle GD. Comparison of supervised exercise with and without manual physical therapy for patients with shoulder impingement syndrome. J Orthop Sports Phys Ther 2000;30:126-37.

10. Kaada B. Treatment of peritendinitis calcarea of the shoulder by transcutaneous nerve stimulation. Acupunct Electrother Res 1984;9:115-25.

11. Wagenhauser FJ. [Clinical physical examination of patients with backache] [German]. Z Allgemeinmed 1972;48:451-69.

12. Rompe JD, Hope C, Kullmer K, Heine J, Burger R. Analgesic effect of extracorporeal shock-wave therapy on chronic tennis elbow. J Bone Joint Surg Br 1996;78:233-7.

13. Green S, Buchbinder R, Glazier R, Forbes A. Systematic review of randomised controlled trials of interventions for painful shoulder: selection criteria, outcome assessment, and efficacy. BMJ 1998;316:354-60.

14. Rompe JD, Buch M, Gerdesmeyer L, et al. [Musculoskeletal shock wave therapy-current database of clinical research] [German]. Z Orthop Ihre Grenzgeb 2002;140:267-74.

15. Cosentino R, Falsetti P, Manca S, et al. Efficacy of extracorporeal shock wave treatment in calcaneal enthesophytosis. Ann Rheum Dis 2001;60:1064-7.

16. Cacchio A, Paoloni M, Barile A, et al. Effectiveness of radial shockwave therapy for calcific tendinitis of the shoulder: single-blind, randomized clinical study. Phys Ther 2006;86:672-82.

17. Rebuzzi E, Coletti N, Schiavetti S, Giusto F. Arthroscopy surgery versus shock wave therapy for chronic calcifying tendinitis of the shoulder. J Orthop Traumatol 2008;9:179-85.

18. Rompe JD, Zoellner J, Nafe B. Shock wave therapy versus conventional surgery in the treatment of calcifying tendinitis of the shoulder. Clin Orthop Relat Res 2001;(387):72-82.

19. Shrivastava SK, Kailash. Shock wave treatment in medicine. J Biosci 2005;30:269-75.

20. Speed CA, Richards C, Nichols D, et al. Extracorporeal shock-wave therapy for tendonitis of the rotator cuff. A double-blind, randomised, controlled trial. J Bone Joint Surg Br 2002;84:509-12.

21. Mouzopoulos G, Stamatakos M, Mouzopoulos D, Tzurbakis M. Extracorporeal shock wave treatment for shoulder calcific tendonitis: a systematic review. Skeletal Radiol 2007;36:803-11 [Epub ahead of print 2007 Apr 6. Review].

22. Ioppolo F, Tattoli M, Di Sante L, et al. Extracorporeal shock-wave therapy for supraspinatus calcifying tendinitis: a randomized clinical trial comparing two different energy levels. Phys Ther 2012;92:137685. 2012 Jun 28. [Epub ahead of print]

23. Dahmen G, Meiss L, Nam V, Skruodies B. [Extrakorporale Sto $\beta$ wellentherapie (ESWT) im knochennahen Weichteilbereich an der Schulter] [German]. Extr Orthop 1992;11:25-7.

24. Hearnden A, Desai A, Karmegam A, Flannery M. Extracorporeal shock wave therapy in chronic calcific tendonitis of the shoulder-is it effective? Acta Orthop Belg 2009;75:25-31.

25. Hsu CJ, Wang DY, Tseng KF, Fong YC, Hsu HC, Jim YF. Extracorporeal shock wave therapy for calcifying tendinitis of the shoulder. J Shoulder Elbow Surg 2008;17:55-9.

26. Cosentino R, De Stefano R, Selvi E, et al. Extracorporeal shock wave therapy for chronic calcific tendinitis of the shoulder: single blind study. Ann Rheum Dis 2003;62:248-50.

27. Peters J, Luboldt W, Schwarz W, Jacobi V, Herzog C, Vogl TJ. Extracorporeal shock wave therapy in calcific tendinitis of the shoulder. Skeletal Radiol 2004;33:712-8.
28. Gerdesmeyer L, Wagenpfeil S, Haake M, et al. Extracorporeal shock wave therapy for the treatment of chronic calcifying tendonitis of the rotator cuff: a randomized controlled trial. JAMA 2003;290:2573-80.

29. Egger M, Smith GD, Altam D. Systematic review in health care. Metaanalysis in context. 2nd ed. London: BMJ Books; 2001.

30. Tashjian RZ, Deloach J, Porucznik CA, Powell AP. Minimal clinically important differences (MCID) and patient acceptable symptomatic state (PASS) for visual analog scales (VAS) measuring pain in patients treated for rotator cuff disease. J Shoulder Elbow Surg 2009;18: 927-32.

31. McCormack HM, Horne DJ, Sheather S. Clinical applications of visual analog scales: a critical review. Psychol Med 1988;18:1007-19.

32. Constant CR, Murley AH. A clinical method of functional assessment of the shoulder. Clin Orthop Relat Res 1987;(214):160-4.

33. Roy JS, MacDermid JC, Woodhouse LJ. A systematic review of the psychometric properties of the Constant-Murley score. J Shoulder Elbow Surg 2010;19:157-64.

34. Amstutz HC, Sew Hoy AL, Clarke IC. UCLA anatomic total shoulder arthroplasty. Clin Orthop Relat Res 1981;(155):7-20.

35. Mariotto S, Cavalieri E, Amelio E, et al. Extracorporeal shock waves: from lithotripsy to anti-inflammatory action by NO production. Nitric Oxide 2005;12:89-96.

36. Perlick L, Korth O, Wallny T, Wagner U, Hesse A, Schmitt O. [The mechanical effects of shock waves in extracorporeal shock wave treatment of calcific tendinitis-an in vitro model] [German]. Z Orthop Ihre Grenzgeb 1999;137:10-6.

37. Uhthoff HK, Loehr J. Calcifying tendinitis. In: Rockwood CA, Matsen FA, editors. The shoulder, 2nd ed. Philadelphia: WB Saunders; 1998.

38. Wagenhauser J. Die periarthropatie-syndrome. Therapiewoche 1972; 37:3187-92.

39. Geschwend N, Patte D, Zippel J. [Therapy of calcific tendinitis of the shoulder] [German]. Arch Orthop Unfallchir 1972;73:120-35.

40. Daecke W, Kusnierczak D, Loew M. Long-term effects of extracorporeal shockwave therapy in chronic calcific tendinitis of the shoulder. J Shoulder Elbow Surg 2002;11:476-80.

41. Loew M, Daecke W, Kusnierczak D, Rahmanzadeh M, Ewerbeck V. Shock-wave therapy is effective for chronic calcifying tendinitis of the shoulder. J Bone Joint Surg Br 1999;81:863-7.

42. Albert JD, Meadeb J, Guggenbuhl P, et al. High-energy extracorporeal shock-wave therapy for calcifying tendinitis of the rotator cuff: a randomised trial. J Bone Joint Surg Br 2007;89:335-41.

43. Klonschinski T, Ament SJ, Schlereth T, Rompe JD, Birklein F. Application of local anesthesia inhibits effects of low-energy extracorporeal shock wave treatment (ESWT) on nociceptors. Pain Med 2011;12:1532-7.

44. Wang CJ, Wang FS, Yang KD, et al. Shock wave therapy induces neovascularization at the tendon-bone junction. A study in rabbits. J Orthop Res 2003;21:984-9.

45. Mariotto S, de Prati AC, Cavalieri E, Amelio E, Marlinghaus E, Suzuki H. Extracorporeal shock wave therapy in inflammatory diseases: molecular mechanism that triggers anti-inflammatory action. Current Med Chem 2009;16:2366-72.

46. Mariotto S, Cavalieri E, Amelio E, et al. Extracorporeal shock waves: from lithotripsy to anti-inflammatory action by NO production. Nitric Oxide 2005;12:89-96. 